DOI 10.37882/2223-2982.2021.12-2.29

\title{
ФРАЗЕОЛОГИЧЕСКИЕ ИНТЕНСИФИКАТОРЫ АНГЛОЯЗЫЧНОГО ЭКОНОМИЧЕСКОГО ДИСКУРСА КАК СРЕДСТВО РЕЧЕВОЙ ЭКСПРЕССИИ
}

\section{PHRASEOLOGICAL INTENSIFIERS OF ENGLISH ECONOMIC DISCOURSE AS A MEANS OF SPEECH EXPRESSION}

S. Orlova

Summary: A distinctive feature of economic discourse is not only the abundance of terminology, cliches, indexes, but also the use of means of speech expression, which represents in a steady need for the use of phraseological units and intensifiers. In economic discourse, phraseological intensifiers are the main pragmatic markers or signals of illocutionary force, contributing to the establishment and development of illocutionary force of speech acts that make up discourse, and functioning as a means of illocutionary semantics of discourse and a means of speech expression.

Keywords: economic discourse, phraseology, intensifier, speech expressiveness.

\author{
Орлова Светлана Николаевна \\ Государственный университет управления \\ topsv@yandex.ru
}

Аннотация: Отличительной чертой экономического дискурса является не только обилие терминологии, клише, индексов, но и использование средств речевой экспрессии, которая проявляется в устойчивой потребности в употреблении фразеологических единиц и интенсификаторов. В экономическом дискурсе фразеологические интенсификаторы являются основными прагматическими маркерами или сигналами иллокутивной силы, способствуя установлению и развитию иллокутивной силы речевых актов, составляющих дискурс, и функционируя как средство иллокутивной семантики дискурса и средством выражения речевой экспрессии.

Ключевые слова: экономический дискурс, фразеология, интенсификатор, экспрессивность.

На протяжении многих лет одной из постоянных областей исследований было изучение влияния выразительности на язык. Лингвисты Дж.Дж. Брадак, Дж.У. Бауэрс и Дж.А. Кортрайт [1] показали положительное влияние интенсивности языка на изменение отношения в общении. Ранние исследования интенсивности языка, основывались на широко принятом определении, предложенном Джоном Уэйтом Бауэрсом, который определил интенсивность языка как «качество языка, которое указывает на степень, в которой отношение говорящего к понятию отклоняется от нейтральности» [2].

Интенсивность языка можно определить как количество иллокутивной силы, которой обладает высказывание, степень силы вербального выражения интенциональности говорящих. Предметом рассмотрения данной статьи является фразеологическое средство категоризации языковой интенсивности, а именно фразеологический интенсификатор

Один из ведущих специалистов по проблемам английской фразеологии профессор А.В. Кунин определил фразеологические интенсификаторы как фразеологические единицы с полностью переданными значениями их составляющих [3]. Он заявил, что составные части фразеологического усилителя полностью изменили свое текущее или буквальное значение, и в результате фразео- 
логическая единица приобрела усиливающее значение. Вот некоторые примеры фразеологических усилителей, используемых в английском языке: like a short - very fast, like mad - furiously, like a house afire - rapidly and with force. Являясь одним из средств категоризации языковой интенсивности, фразеологические интенсификаторы считаются единственным классом фразеологических единиц во фразеологической систематике, который ближе к семиотическому понятию знака, представлены как знаки вторичного предикации, которые используются для усиления качеств, действий, состояний, передаваемых лексическими единицами.

При анализе особенностей фразеологического интенсификатора в экономическом дискурсе можно отметить, что он служит инструментом, используемым участниками для достижения определенных коммуникативных целей, или, другими словами, он передает говорящему прагматическое значение. Намерение говорящего при произнесении высказывания определяется Дж. Серлем и Д. Вандервекеном как иллокутивная сила речевого акта. В экономическом дискурсе фразеологические интенсификаторы являются основными прагматическими маркерами или сигналами иллокутивной силы. Они способствуют установлению и развитию иллокутивной силы речевых актов, составляющих дискурс, другими словами, они функционируют как средство иллокутивной семантики дискурса.

Важно отметить, что фразеологические интенсификаторы являются сигналами иллокутивной силы высказывания только в условиях дополнения диалога, под которым мы понимаем речевое действие, направленное на структурное и семантическое завершение слушателем начальной фразы говорящего. Рассмотрим пример, в котором фразеологический интенсификатор устанавливает иллокутивную силу утверждения:

Заголовок к статье «What on earth is the CPTPP?» [4] представляет собой еще не высказывание, а просто стимул, исходящий от автора статьи и заставляющий читателя прочесть последующий текст: A new trade block emerges from the ashes of the TPP. The prospects for global trade look bleak. Donald Trump has signed controversial orders imposing heavy tariffs on steel and aluminium. China and the EU have threatened to retaliate. But while potential trade wars are hogging the headlines, they are not on the agenda everywhere. On March 8th trade ministers from 11 countries gathered in Santiago, the capital of Chile, to sign the Comprehensive and Progressive Agreement for Trans-Pacific Partnership, or CPTPP. What is this (clunkily acronymised) new deal?

В рассматриваемом примере это фразеологический интенсификатор «What on earth», что буквально означает «Что это еще за» и не обладает семантической неза- висимостью, кроме вопроса. Ответ на иллокутивный акт при этом не ограничен вопросом, который ему предшествует; только будучи взаимно дополняющим, вопрос становится высказыванием с предложением запроса о некоторой информации, а ответ приобретает иллокутивный смысл утверждения.

Рассмотрим второй пример: В статье The Economist «Let's reinvent the bookshop» [5] автор начинает обращение к читателю таким образом: «Bookshops are closing down like nobody's business. So do they need rethinking for the electronic age? Rosanna de Lisle asks four firms of architects and designers to create the bookshop of their dreams». Фразеологический интенсификатор «like nobody's business» имеет значение «без конца, постоянно» и употреблен в своем буквальном значении, при этом его компоненты полностью утратили свои буквальные значения и приобрели целостное интенсифицирующее значение в результате экспрессивного переосмысления на основе метафоризации.

В соответствии с теорией Дж. Серля [6] каждое законченное предложение, даже предложение из одного слова, имеет некоторый показатель иллокутивной силы, в обоих примерах фразеологические интенсификаторы устанавливают иллокутивную силу высказывания, они привлекают внимание слушателя в разговоре и устанавливают взаимопонимание между собеседниками, т. е. передают говорящему прагматический смысл.

Вклад фразеологического интенсификатора в развитие иллокутивной силы дискурса состоит в усилении иллокутивной силы высказывания, составляющие дискурс. Согласно Дж. Р. Серлю и Д. Вандервекену, каждая иллокутивная сила имеет семь взаимосвязанных компонентов [6]:

- иллокутивная точка или цель, которая на сегодняшний день является наиболее важным компонентом;

- степень силы иллокутивной точки зрения;

- способ достижения этой точки,

- условия пропозиционального содержания,

- подготовительные условия,

- условия искренности

- степень силы условий искренности.

Для нашего исследования представляют интерес две составляющие иллокутивной силы, а именно степень сила иллокутивной точки и степень силы условий искренности, так как вклад фразеологического интенсификатора в усиление этих двух компонентов значителен. Иллокутивный момент составляет наиболее важный и основной элемент иллокутивной силы, он определяет цель, намерение высказывания. Большинство иллокутивных моментов могут быть достигнуты с большей или меньшей степенью силы в мире высказывания. Именно степень силы иллокутивной точки позволяет различай- 
те два высказывания одного и того же иллокутивного типа. Таким образом, утвердительная иллокутивная точка зрения, которая убеждает говорящего в истинности высказанного предложения, может быть достигнута посредством заявления, утверждения, предсказания, предположения. Говорящий, который утверждает, заявляет, предсказывает и предполагает, что что-то имеет место, выражает пропозициональное содержание в разной степени силы. Если говорящий предполагает, что что-то имеет место, то степень силы представления о том, что это так, меньше, чем если бы говорящий утверждал, что это так.

Приведенные примеры демонстрируют интенсивность вербального выражения иллокутивной точки с помощью фразеологических усилителей. Одна и та же иллокутивная точка может быть достигнута с разной степенью силы, так и одни и те же условия искренности или намеренное состояние могут быть выражены с разной степенью силы.

Отметим, что все ментальные акты характеризуют- ся сознательностью и интенциональностью, при этом интенсивность - это степень силы выражения интенционального состояния говорящего. Выразить определенное намеренное состояние - значит показать, каким образом наш разум направлен к миру или, другими словами, каким образом наш разум представляет мир. Есть три аспекта, на которые может быть направлено интенциональное состояние, - события, предметы и действия, выполняемые их, объекты и аспекты, присвоенные им. В речевых актах, представленных выше, фразеологические интенсификаторы способствуют интенсивному выражению интенциональных состояний коммуникантов.

В заключение следует подчеркнуть, что сообщения, использующие фразеологические интенсификаторы В качестве средства языка высокой интенсивности, приводят к большему изменению отношения, чем аналогичные сообщения, использующие язык низкой интенсивности. Из этого следует, что в экономическом дискурсе фразеологический интенсификатор имеет конкретную прагматическую направленность и широко используется для воздействия на собеседников.

\section{ЛИТЕРАТУРА}

1. Bradac J.J., Bowers J.W., Courtright J.A., Three language variables in communication research: Intensity, immediacy, and diversity, Human Communication Research 5(3), 257-269, 1979.

2. J.W. Bowers, Language intensity, social introversion, and attitude change. Speech Monographs, 30 (4), 345- 352, 1963.

3. Кунин А.В. Курс фразеологии современного английского языка: Уч. пос. для ин-тов и фак. иностр. яз.- 3-е изд., стереотип./А.В. Кунин. - Дубна: Феникс+, 2005. -488 c.

4. https://www.economist.com/the-economist-explains/2018/03/12/what-on-earth-is-the-cptpp

5. https://www.economist.com/1843/2014/12/28/lets-reinvent-the-bookshop

6. Searle J.R., Vanderveken D., Foundations of Illocutionary Logic/ Cambridge University Press, Cambridge, 1985.

() Орлова Светлана Николаевна (topsv@yandex.ru). 